Article

\title{
Collagenase and Melanogenesis Inhibitory Effects of Perilla Frutescens Pomace Extract and Its Efficacy in Topical Cosmetic Formulations
}

\author{
Lapatrada Mungmai ${ }^{1, *}$, Weeraya Preedalikit ${ }^{1}$ (D), Komsak Pintha ${ }^{2}$, \\ Payungsak Tantipaiboonwong ${ }^{2}$ and Nattapol Aunsri ${ }^{3}{ }^{3}$ \\ 1 Division of Cosmetic Science, School of Pharmaceutical Sciences, University of Phayao, Phayao 56000, \\ Thailand; weeraya.pr@up.ac.th \\ 2 Division of Biochemistry, School of Medical Sciences, University of Phayao, Phayao 56000, Thailand; \\ komsakjo@gmail.com (K.P.); Payungsak.t@gmail.com (P.T.) \\ 3 School of Information Technology and Brain Science and Engineering Innovation Research Group, Mae Fah \\ Luang University, Chiang Rai 57100, Thailand; nattapol.aun@mfu.ac.th \\ * Correspondence: Lapatrada.mu@up.ac.th; Tel.: +66-99-142-8224
}

Received: 9 August 2020; Accepted: 11 September 2020; Published: 14 September 2020

\begin{abstract}
In previous studies, Perilla frutescens pomace was shown to contain bioactive phenolic compounds and good anti-oxidative activity. However, reports about collagenase activity and melanogenesis inhibitory effects of $P$. frutescens pomace are limited. This study aimed to evaluate the bioactivity of $P$. frutescens pomace extract and incorporate the extract into a cosmetic formulation for evaluating its effects on collagenase and melanogenesis inhibition on human skin. The $P$. frutescens seeds after an oil pressing process were extracted with ethanol $(70 \% v / v)$ in order to examine the remaining phytochemical compounds, the bioactivity in pomace perilla, and its efficacy as a skincare product. In this study, total phenolic and total flavonoid contents of $P$. frutescens seed extract (PFSE) were determined using spectrophotometry. The free radical scavenging activity was determined with 2, 2'-diphenyl-1-picrylhydrazyl (DPPH) radicals and 2,2'-azino-bis (3-ethylbenzthiazoline-6-sulphonic acid) ABTS radicals. Additionally, the effects on collagenase activity, melanin content, and alpha-Melanocyte stimulating hormone ( $\alpha$-MSH) on the viability of cultured B16F10 melanoma cells were investigated. Skin irritation and efficacy of PFSE cream for skin elasticity and skin color were also clinically evaluated. The total phenolic content with gallic acid equivalents (GAE) value and total flavonoids content with catechin equivalents (CE) value were, respectively, $92.79 \pm 1.19$ and $56.02 \pm 2.83 \mathrm{mg} / \mathrm{g}$. Furthermore, PFSE significantly inhibited the collagenase activity $(p<0.001)$ at the concentration of $400 \mu \mathrm{g} / \mathrm{mL}(82 \pm 3.23 \%)$. These results clearly demonstrated the anti-melanogenic effects on B16F10 cells without causing any cytotoxicity or death. Although there was a slight improvement in skin elasticity in the 4th week compared to the previous week, the 4th week melanin content of the skin significantly decreased from the beginning $(p<0.05)$ without any irritations. In conclusion, PFSE could be cosmetically considered as a key ingredient that effectively lessens the effects of skin aging and skin hyperpigmentation disorders.
\end{abstract}

Keywords: pomace perilla; collagenase activity; cell viability; melanin content; clinical evaluation

\section{Introduction}

The P. frutescens (L.) Britt. is an aromatic herb, belonging to the family Lamiaceae [1]. Volatile oil extracted from several parts, including stalks, leaves, and seeds, is applied in aromatherapy [2]. Additionally, perilla is not only used as a traditional medicine and functional food throughout Asian countries [3], but also as a fundamental cosmetic ingredient [4,5]. Perilla also gained market importance 
in cosmetics according to its biological activities; different parts of perilla have been differently processed in skin aging creams, serums, gels, and dermatological medicinal preparations [3,6]. The leaves and seeds contain high nutritional value. The leaf is rich in carotenoids while the seed is rich in unsaturated fatty acid [7]. Perilla seeds have been widely used as nutritional and flavoring agents. Moreover, they provides various biological activities such as anticancer, antidiabetic, antiasthma, antimicrobial, antiallergic, anti-inflammatory, and antioxidant effects [3,8,9]. Phytochemical analysis of perilla seeds showed the presence of flavonoids and phenolic compounds, which are secondary metabolites. Apigenin, luteolin, and catechin were major flavonoids present in perilla seeds, whereas rosmarinic acid, caffeic acid, ferulic acid, and caffeic acid-3-O-glucoside were major phenolic compounds identified in perilla seeds [10]. Polyunsaturated fatty acid, sterols, and tocopherols were also present in perilla seeds [11,12]. In the processing industries, the perilla seed oil is prepared by cold press extraction for use as food and supplements. Pomace of perilla, the primary waste after seed oil extraction, is normally the pomace of perilla seeds (by-product) and is used for animal feed owing to its low cost. Guan, 2014 [13] reported that pomace of perilla contains relatively larger amount of rosmarinic acid, rosmarinic acid-3-O-glucoside, luteolin, and apigenin than do perilla seeds. These by-products contain several secondary metabolites that are highly nutritious [13]. Therefore, pomace of perilla after seed oil extraction could also be described as a good resource for phenolic compounds. So, further exploitation of these waste materials for food additives, supplements, and cosmetic ingredients could be more striking. The aim of this research was to investigate an active ingredient for cosmetic products from the by-product of perilla seeds. Therefore, this study may transform pomace into a value-added product and offer the perilla seed oil manufacturers an increase in profitability. This research presents the phytochemical compounds, biological activities such as antioxidant activity, collagenase activity, and melanogenesis, and clinical evaluation of the cosmetic properties of a perilla cream formulation on human skin.

\section{Materials and Methods}

\subsection{Preparation of Extracts}

Pomace of perilla, the seeds after the oil pressing process, were dried $(20 \mathrm{~g})$, macerated with $75 \mathrm{~mL}$ $(70 \% v / v)$ ethanol at room temperature, then centrifuged at $500 \mathrm{rpm}$ for $4 \mathrm{~h}$. The macerated pomace of perilla was allowed to stand at ambient temperature overnight. Consequently, the macerated pomace was filtered and then centrifuged at $1000 \mathrm{rpm}$ for $10 \mathrm{~min}$. The clear supernatant was collected and evaporated at $45-50{ }^{\circ} \mathrm{C}$ under reduced pressure to obtain the crude extract. The crude extracts (P. frutescens seed extract (PFSE)) was dissolved in water, then freeze dried. The extracts were stored at $-20{ }^{\circ} \mathrm{C}$ until further use.

\subsection{Total Phenolic Content}

Total phenolic content was determined using the Folin-Ciocalteau assay. The following method was described by Mungmai, 2019 [4] with slight modifications. Folin-Ciocalteu reageant $(250 \mu \mathrm{L})$ was added to the mixture of $250 \mu \mathrm{L}$ of the extract that was already mixed with $250 \mu \mathrm{L}$ ethanol. The mixture was gently stirred and allowed to stand for $5 \mathrm{~min}$ at room temperature. Then, $250 \mu \mathrm{L}$ of $5 \% w / v \mathrm{Na}_{2} \mathrm{CO}_{3}$ solution was added to the mixture. After incubation for $1 \mathrm{~h}$ in a dark room at room temperature, the absorbance was measured at $725 \mathrm{~nm}$ with an UV-Vis spectrophotometer. The total phenolic content was expressed as $\mathrm{mg}$ gallic acid equivalents antioxidant capacity (GAE; mg gallic acid/g extract). All determinations were carried out in triplicate.

\subsection{Total Flavonoids Content}

The total flavonoids content was determined by the aluminum chloride colorimetric method, which was slightly modified from an existing protocol $[14,15]$. An amount of $0.6 \mathrm{~mL}$ of the extract was mixed with $0.3 \mathrm{~mL}$ of $5 \% \mathrm{NaNO}_{3}$ solution and $0.3 \mathrm{~mL}$ of $10 \% \mathrm{AlCl}_{3}$ solution. Then, $2 \mathrm{~mL}$ of $1 \mathrm{M} \mathrm{NaOH}$ 
solution was added. The mixture stood for $15 \mathrm{~min}$, and absorbance was measured at $510 \mathrm{~nm}$ with a microplate reader. The total flavonoid content was calculated from a calibration curve, and the result was expressed as catechin equivalent $\mathrm{mg}$ catechin/g extract.

\subsection{Antioxidant Properties}

\subsubsection{DPPH Radical Scavenging Assay}

DPPH (2,2'-diphenyl-1-picrylhydrazyl) radical scavenging activity was measured using methods adapted from an existing protocol $[4,16]$. Eight microliters of each extract with different dilutions were added to $67 \mu \mathrm{L}$ of $1 \mathrm{M}$ Tris- $\mathrm{HCl}(\mathrm{pH} 7.9)$ and $800 \mu \mathrm{L}$ of $130 \mu \mathrm{M}$ DPPH radical/methanol solution in a 96-well microtiter plate. The mixture was allowed to stand for $20 \mathrm{~min}$ in the dark at room temperature. Absorbance of the mixtures was measured at $517 \mathrm{~nm}$ with a microplate reader. Ascorbic acid was used as the reference standard. The capability of the sample to scavenge DPPH radicals was expressed as the inhibition percentage of DPPH radical and calculated as follow:

$$
\% \text { inhibition }=\left[\left(\mathrm{A}_{\text {control }}-\mathrm{A}_{\text {sample }}\right) /\left(\mathrm{A}_{\text {control }}\right)\right] \times 100
$$

where $A_{\text {control }}$ is the absorbance of control and $A_{\text {sample }}$ is the absorbance of the sample.

\subsubsection{ABTS radical Scavenging Assay}

ABTS (3-ethylbenzthiazoline-6-sulphonic acid) radical scavenging activity was applied according to the method described by Sridhar and Charles, 2019 [17] with some modifications. The ABTS solution was reacted with $2.45 \mathrm{mM}$ aqueous solution of potassium persulfate at room temperature in the dark for $12 \mathrm{~h}$ to obtained $\mathrm{ABTS}^{\bullet+}$. Then, $1 \mathrm{~mL}$ of $\mathrm{ABTS}^{\bullet+}$ solution was mixed with $0.50 \mathrm{~mL}$ of the aqueous extract at different concentrations. Ascorbic acid was utilized as a reference material. The mixture was then incubated at room temperature for exactly $10 \mathrm{~min}$ in the dark. The results of scavenging activity were calculated as \% inhibition using Equation (1).

\subsection{Collagenase Activity Assay}

Collagenase activity was determined using fluorescein conjugated gelation (Thermo Fisher) as a substrate and using a protocol slightly modified from an existing protocol [18]. The enzyme solution was added to the substrate solution together with a reaction buffer $(0.5 \mathrm{M}$ Tris- $\mathrm{HCl}, 1.5 \mathrm{M} \mathrm{NaCl}, 50 \mathrm{mM}$ $\mathrm{CaCl}_{2}, 2 \mathrm{mM} \mathrm{NaN}_{3}$ (pH 7.6)). Fluorescence intensity for every sample was measured every 2 min for 20 min using a multimode reader. The collagenase concentration was calculated using a calibration curve generated by a collagenase sample of known concentrations.

\subsection{Cell Viability}

The cell viability effect on B16F10 cells was estimated by measuring the reduction of an MTT assay, slightly modified from an existing protocol [19]. B16F10 cells $\left(5 \times 10^{4}\right.$ cells) were cultured in a 96-well plate, then incubated in $5 \% \mathrm{CO}_{2}$ at $37^{\circ} \mathrm{C}$ for $24 \mathrm{~h}$. After that, the test substances at various concentrations $(1.25,2.5,5.0,10,20$, and $40 \mu \mathrm{g} / \mathrm{mL})$ were added into each well, further incubated for $20 \mathrm{~h}$, and treated with MTT solution for $4 \mathrm{~h}$ at $37^{\circ} \mathrm{C}$. MTT solution was consequently removed. The remaining crystals were solubilized in DMSO. The absorbance was measured using an ELISA reader at $570 \mathrm{~nm}$. The percentages of viable cells in each well were calculated relative to the optical density (OD) value of living cells in the control group (100\%). The percentage of cell survival was calculated as follows:

$$
\% \text { cell survival }=\left(\mathrm{OD}_{\text {sample }} / \mathrm{OD}_{\text {control }}\right) \times 100
$$




\subsection{Melanin Content Assay}

The measurement of melanin content in the melanoma cells was slightly modified from an existing protocol $[19,20]$. First, $1 \times 10^{5}$ cells of B16F10 melanoma cell line were cultured in Dulbecco's modified Eagle's medium (DMEM; Capricorn, Germany) supplemented with 10\% fetal bovine serum (FBS; Capricorn, Germany) in a humidified atmosphere containing $5 \% \mathrm{CO}_{2}$ at $37^{\circ} \mathrm{C}$ for $24 \mathrm{~h}$. After $24 \mathrm{~h}$ of incubation with $\alpha$-MSH $(200 \mathrm{nM})$, the medium was replaced with a fresh medium containing various concentrations of the test substances (arbutin $200 \mu \mathrm{g} / \mathrm{mL}$, kojic acid $200 \mu \mathrm{g} / \mathrm{mL}$, and PFSE (10, 20 and $40 \mu \mathrm{g} / \mathrm{mL}$ ). The cells were harvested and washed twice with phosphate-buffered saline (PBS buffer, $\mathrm{pH}$ 7.4) and lysed with RIPA buffer. After removal of the medium, melanin pigment was extracted with $1 \mathrm{~N} \mathrm{NaOH}(200 \mu \mathrm{L})$ at $90{ }^{\circ} \mathrm{C}$ for $1 \mathrm{~h}$. After centrifugation at $3000 \mathrm{rpm}$ for $5 \mathrm{~min}$, the melanin content was determined at $405 \mathrm{~nm}$ using an enzyme-linked immunosorbent assay reader.

\subsection{Clinical Evaluation}

The research protocols were authorized by the University of Phayao Human Ethic Committee, Thailand (approval number was 3/020/61), which operates in accordance with the WHO Guidelines for Good Clinical Practice [21]. The Thai Clinical Trials Registry (TCTR) identification number is TCTR20200508001. The study was carried out on thirty healthy volunteers $(\mathrm{n}=30)$ who all signed a written informed consent form. The measurement conditions were described in Mungmai, 2020 [5]. Inclusion criteria were males and females aged between 35-55 years old; Available for the study duration; and read, understood, and signed an informed consent agreement. Exclusion criteria were visible skin disease at the study site that, in the opinion of the investigator, might interfere the evaluation; using any systemic or topical drugs or taking medication that could mask or interfere with study results; history of serious diseases or sensitivity to cosmetics in general that could interfere with test results; diagnosed with chronic skin allergies; having a known or suspected intolerance or hypersensitivity to the investigational products or any of their ingredients; females who were pregnant or lactating.

\subsubsection{Skin Irritation Patch Test}

The safety assessment method was described with some modifications to protocols $[4,22]$. The primary dermal irritation index (PDII) was used to estimate the irritating reaction. The skin irritation test was investigated using a Finn chamber ${ }^{\circledR}$ that contained test substances: cream base (CB), cream containing P. frutescens seed extract (PSE), 1\% w/v sodium lauryl sulfate (SLS) was as a positive control, and deionized water as a negative control. Finn chambers ${ }^{\circledR}$ were covered on the upper back of the volunteers for $48 \mathrm{~h}$. After that, participants were monitored for any irritating reactions, including erythema and edema formations, at 1,24 , and $48 \mathrm{~h}$ after removal of the patch.

\subsubsection{Efficacy Testing}

Skin elasticity: The volunteers were asked to apply $0.2 \mathrm{~g}$ of each test product (CB, PFSE) to the testing area on each site of their face twice daily (morning and evening) for 4 weeks. Results were collected and analyzed at the beginning (week 0), 3rd, and 4th week. The skin elasticity was assessed with an elasticity probe (Dermalab Combo ${ }^{\circledR}$ Series; Cortex Technology ApS, Hadsund, Denmark).

Skin color: The measurements of the skin color were conducted with a skin color probe (Dermalab Combo $^{\circledR}$ Series; Cortex Technology ApS, Hadsund, Denmark). The results of the measurements were expressed as melanin content. Every parameter was measured thrice and averaged.

\subsection{Statistical Analysis}

Statistical analysis was performed using SPSS Software, version 17.0 for Windows (SPSS Inc., Chicago, IL, USA) and results were presented as the mean \pm standard deviation for quantitative 
variables. Skin parameters at 4 th week were compared with baseline values using paired sample $t$-test, and the statistical significance was set at $p$-values less than 0.05 and 0.001 .

\section{Results and Discussion}

\subsection{Total Phenolic Content, Total Flavonoid Content, and Free Radical Scavenging Activity}

PFSE had total phenolic and total flavonoid contents as shown by GAE and catechin equivalent (CE) values, respectively, of $92.79 \pm 1.19$ and $56.02 \pm 2.83 \mathrm{mg} / \mathrm{g}$. Phenolic and flavonoids compounds may contribute directly to antioxidative action, which facilitates the prevention of damage to cells caused by free radicals. The radical scavenging activity of the extract was compared with ascorbic acid and expressed as the concentration required to achieve a $50 \%$ reduction in radicals $\left(\mathrm{IC}_{50}\right)$. DPPH and ABTS scavenging assays were performed. The extract showed the DPPH scavenging activity with an $\mathrm{IC}_{50}$ of $86.06 \pm 5.65 \mu \mathrm{g} / \mathrm{mL}$, lower than that of ascorbic acid $(3.07 \pm 0.18 \mu \mathrm{g} / \mathrm{mL})$. The ABTS assay presented an $\mathrm{IC}_{50}$ of $24.84 \pm 2.21 \mu \mathrm{g} / \mathrm{mL}$, which is lower than that of ascorbic acid $(2.68 \pm 0.12 \mu \mathrm{g} / \mathrm{mL})$. These results are listed in Table 1. The DPPH and ABTS tests reveal the hydrogen atom or electron donating capacity of the extract to the stable radical formed in solution [15]. The high antioxidant activity indicated the scavenging potential of the extract in terms of its hydrogen donating ability [23].

Table 1. Total phenolic and total flavonoid contents and free radical scavenging activity of pomace of perilla.

\begin{tabular}{|c|c|c|c|c|c|c|}
\hline \multirow{2}{*}{$\begin{array}{c}\text { Test } \\
\text { Materials }\end{array}$} & \multirow{2}{*}{$\begin{array}{l}\text { Total Phenolic Content } \\
\text { (mg GAE/g Extract } \pm \text { SD) }\end{array}$} & \multirow{2}{*}{$\begin{array}{l}\text { Total Flavonoids Content } \\
\text { (mg CE/g Extract } \pm \text { SD) }\end{array}$} & \multicolumn{2}{|c|}{ DPPH• Assay } & \multicolumn{2}{|c|}{ ABTS• Assay } \\
\hline & & & $\begin{array}{c}\text { Ascorbic Acid } \\
\mathrm{IC}_{50} \pm \mathrm{SD}(\mu \mathrm{g} / \mathrm{mL})\end{array}$ & $\begin{array}{c}\mathrm{IC}_{50} \pm \mathrm{SD} \\
(\mu \mathrm{g} / \mathrm{mL})\end{array}$ & $\begin{array}{c}\text { Ascorbic Acid } \\
\mathrm{IC}_{50} \pm \mathrm{SD}(\mu \mathrm{g} / \mathrm{mL})\end{array}$ & $\begin{array}{c}\mathrm{IC}_{50} \pm \mathrm{SD} \\
(\mu \mathrm{g} / \mathrm{mL})\end{array}$ \\
\hline PFSE & $92.79 \pm 1.19$ & $56.02 \pm 2.83$ & $3.07 \pm 0.18$ & $86.06 \pm 5.65$ & $2.68 \pm 0.12$ & $24.84 \pm 2.21$ \\
\hline
\end{tabular}

$\mathrm{PFSE}=$ P. frutescens seed extract; $\mathrm{GAE}=$ gallic acid equivalents; $\mathrm{CE}=$ catechin equivalents. Values are reported as mean \pm standard deviation (SD).

\subsection{Collagenase Inhibition Activity}

The extracts were tested for collagenase activity using collagenase from Clostridium histolyticum. The low percentage of collagenase activity indicated that the extract potentially inhibited collagenase activity. The results revealed that PFSE at the concentration $400 \mu \mathrm{g} / \mathrm{mL}(82.0 \pm 3.23 \%)$ showed significant $(p<0.001)$ inhibitory effects of collagenase activity that can decrease MMP1 enzymatic activity (Figure 1). The illustrated results indicate that the antioxidant activity of the extract is mainly from its phenolic and flavonoid compounds. Flavonoids had been reported for their inhibitory effects on collagenase activity [24], whereas a study on phenolic content showed no correlation with anti-collagenase activity [25]. The pomace of perilla could be considered as a potential source of anti-collagenase agents.

\subsection{Cell Viability and Assessment of Melanin Content}

B16F10 cells were treated with PFSE at various concentrations $(1.25,2.5$, and $40, \mu \mathrm{g} / \mathrm{mL})$ or with $200 \mu \mathrm{g} / \mathrm{mL}$ of arbutin acid or kojic acid. Figure 2a illustrates that all concentrations of PFSE except $40 \mu \mathrm{g} / \mathrm{mL}$ provided a relatively high percentage of cell viability compared to that with $200 \mu \mathrm{g} / \mathrm{mL}$ of arbutin acid or kojic acid. The inhibitory effect on melanogenesis of PFSE at various concentrations were similar to those of the cell viability study and are shown in Figure $2 \mathrm{~b}$. $\alpha$-MSH stimulates the production and release of melanin 5.5-fold. Interestingly, 10, 20, and $40 \mu \mathrm{g} / \mathrm{mL}$ PFSE, $200 \mu \mathrm{g} / \mathrm{mL}$ arbutin, and $200 \mu \mathrm{g} / \mathrm{mL}$ kojic acid lessened the melanin content significantly to $82.7 \pm 3.4(p<0.05)$, $78.7 \pm 7.2(p<0.01), 71.1 \pm 8.2(p<0.001), 46.3 \pm 0.95(p<0.001)$, and $51.5 \pm 5.2 \%(p<0.001)$, respectively. The decrease in melanin content was found to be a dose-dependent activity. These results demonstrate the straightforward anti-melanogenic effects of PFSE at the optimum concentration on B16F10 cells without inducing cytotoxicity or death of cells. The relationship between the antioxidant effects and anti-melanogenesis was shown by high oxidative stress and UV rays along with increased melanin 
production in melanocytes; radical inhibitors and scavenging agents reduce melanin content and decrease hyperpigmentation and melanogenesis caused by oxidative stress [26,27]. Thus, the inhibition of melanogenesis can be achieved by antioxidation; the extract of pomace of perilla should be further investigated for potential use as an ingredient in skin whitening cosmetics.

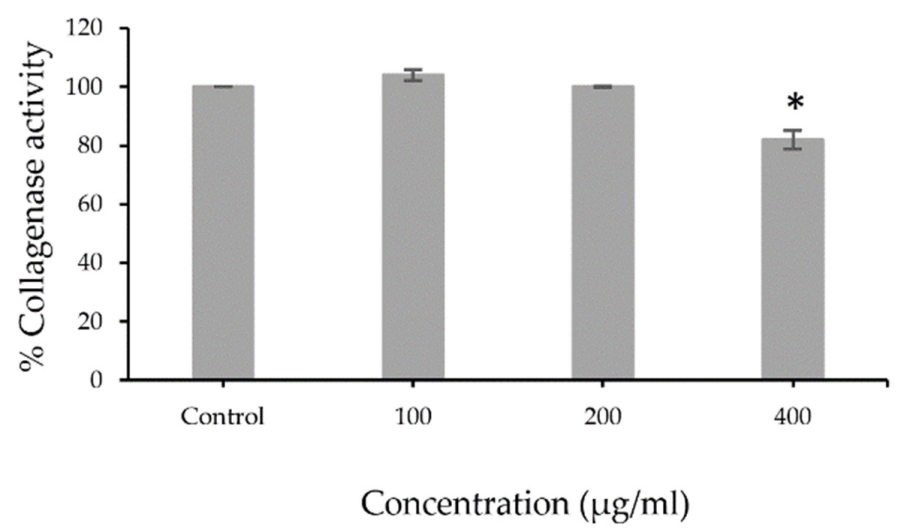

Figure 1. Percentage of collagenase activity of PFSE (100, 200, or $400 \mu \mathrm{g} / \mathrm{mL})$ compared with control. Values are reported as mean \pm standard deviation (SD) and used the paired $t$-test for significance compared with controls. ${ }^{*} p$-value $<0.001$.

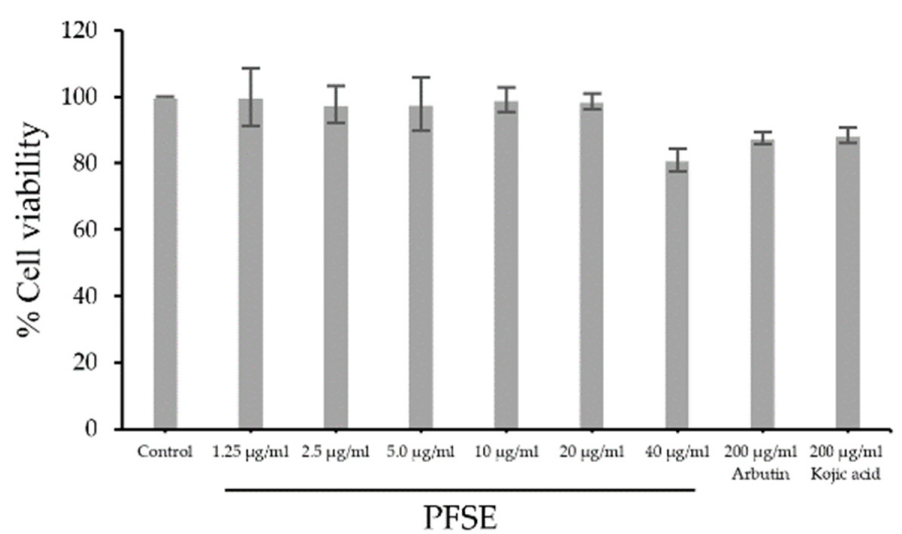

(a)

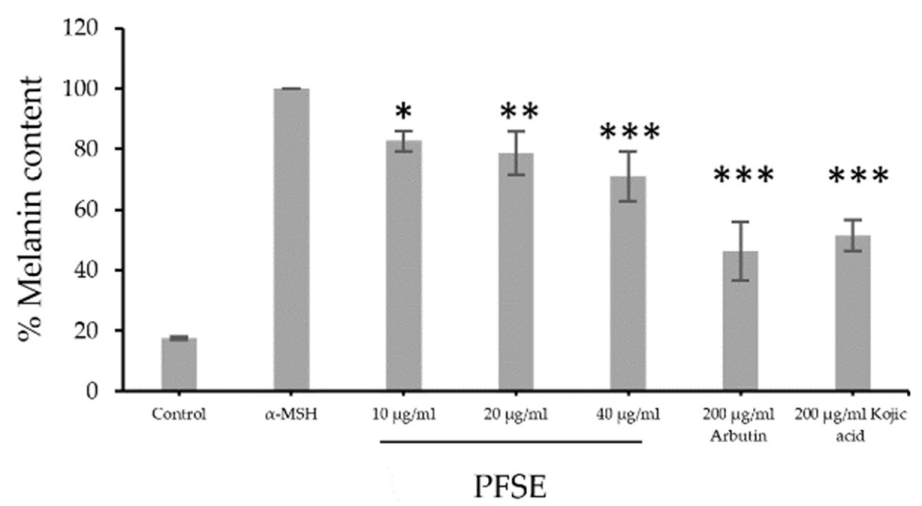

(b)

Figure 2. Effects of PFSE on (a) the viability of B16F10 treated with PFSE $(1.25,2.5,5,10,20$, or $40 \mu \mathrm{g} / \mathrm{mL}$ ) and (b) melanogenesis compared to those of arbutin and kojic acid. Values are reported as mean \pm standard deviation (SD) and used the paired $t$-test for significance compared with controls. ${ }^{*} p$-value $<0.05,{ }^{* *} p$-value $<0.01,{ }^{* * *} p$-value $<0.001$. 


\subsection{Clinical Evaluation}

\subsubsection{Skin Irritation Patch Testing}

After the application of PFSE cream, skin irritation on the upper back of the volunteers was evaluated. The results indicated that at 1, 24, and $48 \mathrm{~h}$ after patch test, all applicants applying Deionized water (DIW), Cream base (CB), and P. frutescens pomace extract (PFSE) cream showed neither the formations of erythema nor edema (PDII value $=0.00)$. Table 2 indicates that the selected materials produced a PDII of 0.00 and were clearly categorized as a non-irritant or corrosive effect. On the other hand, applicants applying 1\% w/v SLS showed a slight formation of erythema or dryness across most of the treatment sites with PDII value at 1.53 .

Table 2. The primary dermal irritation index (PDII) and skin irritation reaction observed in thirty healthy volunteers.

\begin{tabular}{ccc}
\hline Test Materials & PDII Value & Classification of Irritancy \\
\hline $1 \% w / v$ SLS & 1.53 & Mild irritant \\
DIW & 0.00 & Non-irritant \\
CB cream & 0.00 & Non-irritant \\
PFSE cream & 0.00 & Non-irritant \\
\hline
\end{tabular}

\subsubsection{Efficacy Testing}

Skin elasticity testing included the values of modulus of elasticity and retraction time (RT) using suction testing to assess the elastic fibers as the mechanical properties of the skin. The skin elasticity was measured as a percentage of skin retraction after the stretching. The results showed that Young's modulus value of the skin stress at the 4th week was insignificantly higher than that at the 3rd week $(p>0.05)$ (Figure 3a). The skin retraction times after applying CB and PFSE cream are presented in Figure $3 b$. The retraction time after PFSE cream application at the 4 th week significantly decreased from baseline. Generally, retraction time is defined as the duration required for the skin to return to the original position after suction that raises the skin $1.00 \mathrm{~mm}$ higher than the previous position.

The skin after the application of CB cream had significantly higher retention time $(p<0.05)$ than it did after the application of PFSE cream. Although there were no significant differences of the elasticity modulus, the significant decrease of the retention time of the skin after applying the PFSE cream implied remarkable improvement. The results indicated that PFSE cream could improve skin elasticity; this must be confirmed with further investigation.

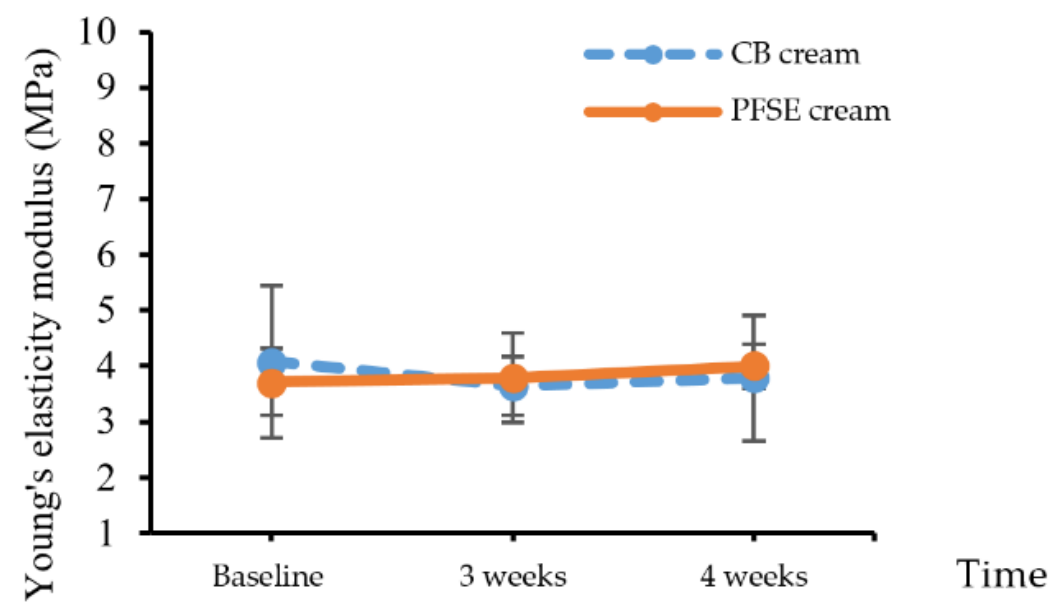

(a)

Figure 3. Cont. 


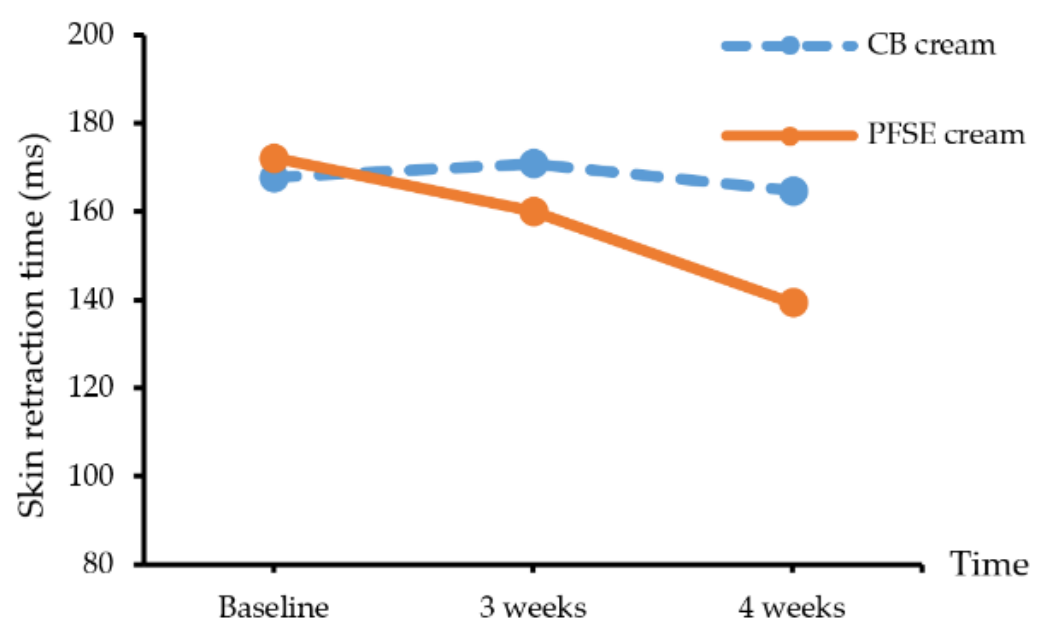

(b)

Figure 3. (a) Young's elasticity modulus value and (b) skin retraction time of the CB and PFSE cream users. Values are reported as mean \pm standard deviation (SD) and used the paired t-test for significance compared with controls. ${ }^{*} p$-value $<0.05$.

The melanin content of the skin with the application of PFSE cream at the 4th week was significantly decreased from the that at the initial application, while $\mathrm{CB}$ cream did not show any consistent differences during the period of study $(p<0.05)$ (Figure 4$)$. The results revealed that the PFSE cream significantly reduced the pigmentation.

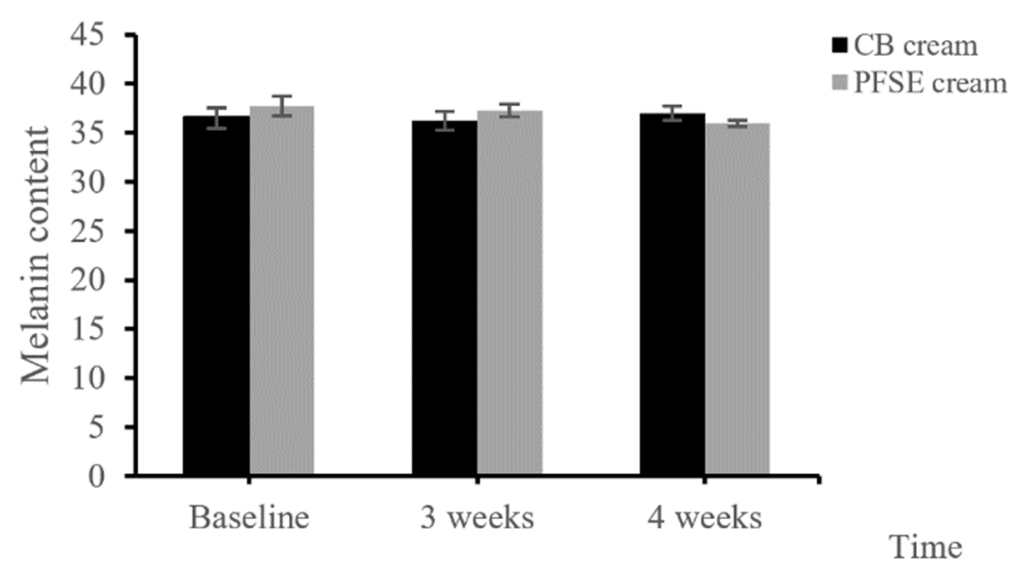

Figure 4. Melanin content of the CB and PFSE cream users. Values are reported as mean \pm standard deviation (SD) and used the paired $t$-test for significance compared with controls. ${ }^{*} p$-value $<0.05$.

\section{Conclusions}

The PFSE had total phenolic and total flavonoid compounds that exhibited antioxidant activities. The components of this extract exhibited collagenase inhibitory effects with anti-melanogenesis in correlation with their antioxidant potential in vitro. Moreover, PFSE exhibited an anti-melanogenic effect on B16F10 cells without inducing cytotoxicity of cells. PFSE cream clinically improved skin elasticity and reduce hyperpigmentation without any skin irritations. The possible mechanism could be the effect of phenolic and flavonoid compounds such as rosmarinic acid and caffeic acid. N. Matwiejczuk et al., 2020 [28] found that rosmarinic acid could protect human skin fibroblasts from paraben-induced biosynthesis, secretion, and degradation of collagen via pERK1/1, MMP1/2, and TIMP1/2. Based on these results, PFSE, the residue from the perilla seed oil extraction, could be suggested as a 
promising source for anti-collagenase and anti-melanogenesis agents and as a potential ingredient in pharmaceuticals and cosmeceuticals intended for the maintenance of collagen structures, slowing down skin aging and melanogenesis processes, and prevention of skin hyperpigmentation disorders.

Author Contributions: Conceptualization, L.M.; methodology, L.M., K.P., and P.T.; software, N.A.; validation, L.M., W.P., and K.P.; formal analysis, L.M.; investigation, L.M. and W.P.; writing-original draft preparation, L.M.; writing-review and editing, N.A. All authors have read and agreed to the published version of the manuscript.

Funding: This research was funded by University of Phayao, grant number RD61051.

Conflicts of Interest: The authors declare no conflict of interest.

\section{References}

1. Zhou, X.-J.; Yan, L.-L.; Yin, P.-P.; Shi, L.-L.; Zhang, J.-H.; Liu, Y.; Ma, C. Structural characterisation and antioxidant activity evaluation of phenolic compounds from cold-pressed Perilla frutescens var. arguta seed flour. Food Chem. 2014, 164, 150-157. [CrossRef] [PubMed]

2. Povilaityee, V.; Venskutonis, P.R. Antioxidative activity of purple peril (Perilla frutescens L.), moldavian dragonhead (Dracocephalum moldavica L.), and roman chamomile (Anthemis nobilis L.) extracts in rapeseed oil. J. Am. Oil Chem. Soc. 2000, 77, 951-956. [CrossRef]

3. Ahmed, H.M. Ethnomedicinal, Phytochemical and Pharmacological Investigations of Perilla frutescens (L.) Britt. Molecules 2018, 24, 102. [CrossRef] [PubMed]

4. Mungmai, L.; Preedalikit, W.; Aunsri, N.; Peerakam, N. Bioactivity test and GC-MS analysis of different solvent extracts from Perilla frutescens (Linn.) Britton and cosmetic product application for sensitive skin. Sci. Tech. RMUTT J. 2019, 9, 78-93.

5. Mungmai, L.; Preedalikit, W.; Aunsri, N.; Amornlerdpison, D. Efficacy of cosmetic formulation containing Perilla frutescens leaves extract for irritation and aging skin. Biomed. Pharmacol. J. 2020, 13, 779-787. [CrossRef]

6. Pintathong, P.; Chaiwut, P.; Thitipramote, N.; Thitilertdecha, N.; Nantitanont, W.; Sangthong, S.; Tiensri, N. Simultaneous extraction of oil and protein from perilla seed by three-phase partitioning and their application in serum. J. Appl. Sci. 2018, 17, 73-84. [CrossRef]

7. Ding, Y.; Neo, C.M.; Hu, Y.; Shi, L.; Chao, M.; Liu, Y. Characterization of fatty acid composition from five perilla seed oils in China and its relationship to annual growth temperature. J. Med. Plants Res. 2012, 6, 1645-1651. [CrossRef]

8. Izumi, Y.; Matsumura, A.; Wakita, S.; Akagi, K.-I.; Fukuda, H.; Kume, T.; Irie, K.; Takada-Takatori, Y.; Sugimoto, H.; Hashimoto, T.; et al. Isolation, identification, and biological evaluation of Nrf2-ARE activator from the leaves of green perilla (Perilla frutescens var. crispa f. viridis). Free. Radic. Biol. Med. 2012, 53, 669-679. [CrossRef]

9. Dhyani, A.; Chopra, R.; Garg, M. A Review on Nutritional Value, Functional Properties and Pharmacological Application of Perilla (Perilla Frutescens L.). Biomed. Pharmacol. J. 2019, 12, 649-660. [CrossRef]

10. Peng, Y.; Ye, J.; Kong, J. Determination of Phenolic Compounds inPerilla frutescensL. by Capillary Electrophoresis with Electrochemical Detection. J. Agric. Food Chem. 2005, 53, 8141-8147. [CrossRef]

11. Meng, L.; Lozano, Y.; Bombarda, I.; Gaydou, E.M.; Li, B. Polyphenol extraction from eight Perilla frutescens cultivars. Comptes Rendus Chim. 2009, 12, 602-611. [CrossRef]

12. Sirilun, S.; Sivamaruthi, B.S.; Pengkumsri, N.; Saelee, M.; Chaiyasut, K.; Tuntisuwanno, N.; Suttajit, M.; Peerajan, S.; Chaiyasut, C. Impact of different pre-treatment strategies on the quality of fatty acid composition, tocols content and metabolic syndrome related activities of Perilla frutescens seed oil. J. Appl. Pharm. Sci. 2016, 6, 1-8. [CrossRef]

13. Guan, Z.; Li, S.; Lin, Z.; Yang, R.; Zhao, Y.; Liu, J.; Yang, S.-M.; Chen, A. Identification and Quantitation of Phenolic Compounds from the Seed and Pomace of Perilla frutescens Using HPLC/PDA and HPLC-ESI/QTOF/MS/MS. Phytochem. Anal. 2014, 25, 508-513. [CrossRef] [PubMed]

14. Chandra, S.; Khan, S.; Avula, B.; Lata, H.; Yang, M.H.; ElSohly, M.A.; Khan, I.A. Assessment of Total Phenolic and Flavonoid Content, Antioxidant Properties, and Yield of Aeroponically and Conventionally Grown Leafy Vegetables and Fruit Crops: A Comparative Study. Evid. Based Complement. Altern. Med. 2014, 2014, 1-9. [CrossRef] [PubMed] 
15. Tepe, B.; Daferera, D.; Sokmen, A.; Sökmen, M.; Polissiou, M. Antimicrobial and antioxidant activities of the essential oil and various extracts of Salvia tomentosa Miller (Lamiaceae). Food Chem. 2005, 90, 333-340. [CrossRef]

16. Duan, X.; Jiang, Y.; Su, X.; Zhang, Z.; Shi, J. Antioxidant properties of anthocyanins extracted from litchi (Litchi chinenesis Sonn.) fruit pericarp tissues in relation to their role in the pericarp browning. Food Chem. 2007, 101, 1365-1371. [CrossRef]

17. Sridhar, K.; Charles, A.L. In vitro antioxidant activity of Kyoho grape extracts in DPPH and ABTS assays: Estimation methods for EC50 using advanced statistical programs. Food Chem. 2019, 275, 41-49. [CrossRef]

18. Zinger, A.; Adir, O.; Alper, M.; Simon, A.; Poley, M.; Tzror, C.; Yaari, Z.; Krayem, M.; Kasten, S.; Nawy, G.; et al. Proteolytic Nanoparticles Replace a Surgical Blade by Controllably Remodeling the Oral Connective Tissue. ACS Nano 2018, 12, 1482-1490. [CrossRef]

19. Preedalikit, W.; Pintha, K.; Tantipaiboonwong, P.; Aunsri, N.; Vivattanaseth, P.; Mungmai, L. Inhibitory Effect of Perilla frutescens L. Leaves Extract on Melanogenesis and Skin Whitening Efficacy in the Underarm Whitening Product Application. Key Eng. Mater. 2020, 859, 166-171. [CrossRef]

20. Lim, J.W.; Ha, J.H.; Jeong, Y.J.; Park, S.N. Anti-melanogenesis effect of dehydroglyasperin C through the downregulation of MITF via the reduction of intracellular cAMP and acceleration of ERK activation in B16F1 melanoma cells. Pharmacol. Rep. 2018, 70, 930-935. [CrossRef]

21. World Health Organization. Handbook for Good Clinical Research Practice (GCP): Guidance for Implementation; World Health Organization: Geneva, Switzerland, 2005.

22. Acute Dermal Irritation/Corrosion 404. OECD Guideline for the Testing Chemicals; OECD Publishing: Paris, France, 2002.

23. Francis, M.A.; Rew, W.V.; Awah, F.M.; Verla, R.W. Antioxidant activity, nitric oxide scavenging activity and phenolic contents of Ocimum gratissimum leaf extract. J. Med. Plants Res. 2010, 4, 2479-2487. [CrossRef]

24. Mandrone, M.; Lorenzi, B.; Venditti, A.; Guarcini, L.; Bianco, A.; Sanna, C.; Ballero, M.; Poli, F.; Antognoni, F. Antioxidant and anti-collagenase activity of Hypericum hircinum L. Ind. Crop. Prod. 2015, 76, 402-408. [CrossRef]

25. Mansauda, K.L.R.; Anwar, E.; Nurhayati, T. Antioxidant and Anti-Collagenase Activity of Sargassum plagyophyllum Extract as an Anti-Wrinkle Cosmetic Ingredient. Pharmacogn. J. 2018, 10, 932-936. [CrossRef]

26. Junlatat, J.; Fangkrathok, N.; Sripanidkulchai, B. Antioxidative and melanin production inhibitory effects of Syzygium cumini extracts. Songklanakarin J. Sci. Technol. 2018, 40, 1136-1143.

27. Kao, Y.-Y.; Chuang, T.-F.; Chao, S.-H.; Yang, J.-H.; Lin, Y.-C.; Huang, H.-Y. Evaluation of the Antioxidant and Melanogenesis Inhibitory Properties of Pracparatum Mungo (Lu-Do Huang). J. Tradit. Complement. Med. 2013, 3, 163-170. [CrossRef]

28. Matwiejczuk, N.; Galicka, A.; Zareba, I.; Brzoska, M.M. The Protective Effect of Rosmarinic Acid against Unfavorable Influence of Methylparaben and Propylparaben on Collagen in Human Skin Fibroblasts. Nutrients 2020, 12, 1282. [CrossRef]

(C) 2020 by the authors. Licensee MDPI, Basel, Switzerland. This article is an open access article distributed under the terms and conditions of the Creative Commons Attribution (CC BY) license (http://creativecommons.org/licenses/by/4.0/). 